\title{
The changing influence of city-systems on global shipping networks: an empirical analysis
}

\author{
César Ducruet ${ }^{*}$ (D), Sylvain Cuyala and Ali EL Hosni
}

\author{
* Correspondence: \\ cdu@parisgeo.cnrs.fr \\ Centre National de la Recherche \\ Scientifique (CNRS), UMR 8504 \\ Géographie-cités, 13 rue du Four, \\ F-75006 Paris, France
}

\begin{abstract}
This paper revisits the classical issue of port-city relationships by applying for the first time network analytical methods to maritime flows connecting cities of the world, over the period 1950-1990. A global matrix of interurban vessel flows was elaborated for about 600 cities using data from the Geopolis and Lloyd's Shipping Index databases and the rigorous assignment of ports to both coastal and inland urban areas. Main results show that although the largest cities have witnessed a diminishing importance in world traffic, they have maintained their dominance in the network in terms of centrality and geographic reach. This research thus contributes to question the ineluctable separation between ports and cities which dominated the literature, while offering new empirical evidence about the structure and dynamics of city-systems and spatial networks in general.
\end{abstract}

Keywords: City-system, Graph theory, Maritime network, Urban development, World shipping

\section{Introduction}

Port cities and maritime networks are at center stage in a world where about $90 \%$ of trade volumes are carried by sea, and a large proportion of the population concentrates on the shoreline (Noin 1999). These "brides of the sea" (Broeze 1989) are specific as they connect foreland and hinterland through the port (Vigarié 1979; Pearson 1998). Major cities of the world are still in many ways maritime cities (Dogan 1988) or locate near seaports or sea-river ports (Vance 1970). Port cities have also been vital centers of successive world systems throughout history (Braudel 1979), from Tyr and Sidon in the Phoenician world to New York and Shanghai nowadays.

However, economic geography and regional science have persistently ignored maritime transport in their conceptualization and empirical analyses of city-systems. Urban development was often considered within land-based systems, such as the central place theory and the New Economic Geography (see Beyer and Fowler, 2012 for a review of urban models), despite early calls for the further integration of port cities in such models (Bird 1977, 1983). This is particularly surprising, given the interest of early economic geographers for maritime trade patterns, such as Edward Ullman (1949), a famous specialist of spatial interaction and cities, for whom maritime flows were "useful to take the pulse of world trade and movement". A recent review of port

(c) 2016 The Author(s). Open Access This article is distributed under the terms of the Creative Commons Attribution 4.0 International License (http://creativecommons.org/licenses/by/4.0/), which permits unrestricted use, distribution, and reproduction in any medium, provided you give appropriate credit to the original author(s) and the source, provide a link to the Creative Commons license, and indicate if changes were made. 
geography papers published since the 1950s showed that human geography gradually lost interest in ports and maritime transport, while port and maritime geographers became increasingly specialized in operation and management (Ng and Ducruet 2014).

As a result, "maritime functions are no longer considered by researchers who establish rankings of world cities competing for the control and domination of the world economy" (Bretagnolle 2015, p. 34). More likely were analyses of interurban connectivity through telecommunications, roads, highways, railways, which was extended later in the 1990s and after to airlines, multinational firms' linkages, and the Internet. One only exception had been the PhD dissertation of Ross Robinson (1968) on the maritime network linking Vancouver and other British Columbia ports, but it is only in the late 1990s that such an approach had been revived, yet without an explicit reference to cities (see Ducruet 2015 for a synthesis). To date, very few attempts were made to fill such a gap, such as the measurement of cities' global accessibility combining multiple layers of which maritime flows (Nelson 2008), the analysis of combined maritime and airline flows (Parshani et al. 2010), and the analysis of maritime flows in relation to subnational socio-economic features in the Asia-Pacific region (Ducruet and Itoh 2015). The maritime mode was even absent of studies of systems of cities combining two or more transport networks (see Derudder et al. 2014). But these studies remain highly static and cannot account for the evolution of the linkages between maritime transport and urban development. Other studies focusing on airline traffic networks had discussed urban aspects but in the recent period only and at country or continent level (see Dobruszkes et al. 2011; Neal 2011). Another parent type of study had been the analysis of the location of maritime Advanced Producer Services (APS) in world cities (Verhetsel and Sel 2009), pointing to the limited influence of total container port throughput, among other variables, on the amount of such APS (Jacobs et al. 2011). Physical maritime flows among cities of the world remain a much underexplored area to date.

In her recent essay on city-systems and maritime transport in the long-term, Anne Bretagnolle (2015) proposes one possible explanation to this state of affairs, by defining three successive stages by which maritime flows had become less and less important to urban development. A first stage in the $13^{\text {th }}$ to $18^{\text {th }}$ centuries was characterized by weak interurban links and a crucial role of maritime transport in urban development, as seen in the Middle-Ages with the Hanseatic League, a North European system of cities predominantly connected by water, and the Italian city-states such as Genoa and Venice (see also Gipouloux 2009), but also long-distance trade in the colonial era as exemplified by Adam Smith (1776):

"What goods could bear the expence of land-carriage between London and Calcutta? Those two cities, however, at present carry on a very considerable commerce with each other, and by mutually affording a market, give a good deal of encouragement to each other's industry"

A second stage from the $19^{\text {th }}$ to the mid-20 th century witnessed strong links between cities, while maritime transport became articulated with railroads and canals, giving birth to numerous world gateway cities, through a positive feedback process between accessibility and centrality, connecting local and national scales with the global; however: 
"The third and current stage (second half of the twentieth century and after) is characterized by a weak relationship between maritime transport and world cities. Because of cheap cost-distances, maritime transport still plays a huge role in the globalization of exchange for bulky and low-value merchandise but is much less determinant than air transport, rapid train, and information technology in the selection process of world cities, based on time-distance parameters"

(Bretagnolle 2015, pp. 28-29)

Interestingly, the third stage witnessed the emergence of spatial and functional models of port-city separation. At the local scale (e.g. estuary), the British geographer James Bird (1963) described the recurrent shift of modern port facilities from upstream urban centers to downstream, deep-sea locations in his Anyport model. This phenomenon continued in the following decades (Hoyle 1989; Murphey 1989), combining physical with functional-economical separation (see also $\mathrm{Ng}$ et al. 2014 for a synthesis), and resulting in numerous cases of waterfront redevelopment for new urban uses (Norcliffe et al. 1996). Maritime economists as well recurrently observed the loosening economic impacts of port activities on their host cities and regions (Musso et al. 2000). These structural changes explain, at least partly, the drastic absence of any empirical analysis of how cities, more than ports, connect through maritime networks.

Various elements, however, motivate such an investigation. First, numerous studies pointed at the permanency of port-city linkages, arguing that while port-city relations may vary in time and space (Lee et al. 2008), cities continue to offer valuable externalities to ports (Hall and Jacobs 2012) and remain vital elements of commodity chains (Hall and Hesse 2012) despite the loosening ability of maritime transport to foster urban development (Fujita and Mori 1996; Bretagnolle 2015). Second, the wider research field of network analysis, complex networks, and spatial networks is a buoyant interdisciplinary area, but where empirical evidence on the effects of nodes' characteristics on network's spatial embedding, topological structure, and growth dynamics remains rather scarce (Ducruet and Lugo 2013; Ducruet and Beauguitte 2014; Barthelemy 2015). Thirdly, recent studies pointed at the "return of the port into the city" (El Hosni 2015), based on the cases of London, Taipei, Tokyo, and Osaka, where several factors ${ }^{1}$ combined to re-shift modern container terminals in the urban space. Such evidence suggests that port-city relationships may in fact be cyclical, thus questioning the linearity of the aforementioned evolutionary models (see Bretagnolle et al. 2009). Last and fourthly, this paper benefits from the availability of historical records of merchant vessel movements throughout the world published by the maritime insurance company Lloyd's List. Such a data source allows measuring harmoniously the intensity of maritime trade at and between ports of the world, and has never been used for the purpose of verifying changing port-city relationships.

The main hypothesis of this paper is the spatial distribution of maritime networks is not only influenced by technological and economic factors, but also by the inherent qualities of the connected places. The period 1950-1990 was chosen as it corresponds to drastic changes in shipping technologies, world trade patterns, and urban growth, with the container revolution emerging and spreading globally (Bernhofen et al. 2013; Guerrero and Rodrigue 2014), resulting in fostered competition and hierarchical tendencies among world ports (see also Slack 1993), as described in the third stage above. 
The remainder of this paper are as follows. The next section presents the data and methodology used for building a global maritime network based on an urban-port database where nodes are cities characterized by a demographic size, taken as a proxy of wider local economic weight. A new methodology is proposed to assign each port to a city or urban area to investigate how this intensity is distributed across the global urban hierarchy. The third section applies a variety of statistical and graph-theoretical methods to answer our main hypothesis. The last section concludes about the outcomes of this research and their usefulness to further understand maritime transport and ports in particular, network structures and dynamics in general.

\section{The global maritime-urban database}

\section{Maritime network construction}

Among all existing maritime data, the Lloyd's List, a world leader in shipping intelligence, is the only possible source capable of documenting the global distribution of maritime flows in a disaggregated manner and over time. The Lloyd's Shipping Index had been published daily or weekly since 1880 on a regular basis since the late nineteenth century. It contains information about vessels and their latest inter-port movement at the date of the publication. For the purposes of this research, it was decided to extract from paper sources one publication every 5 years between 1950 and 1990, around April-May, and to compute the number of vessel calls per port and per inter-port link. Each 200-page publication thus provides a comparable snapshot of global maritime activity covering approximately 1 week of movements. The difficult readability of the printed original documents could not yet allow for the extraction of all information, namely the tonnage capacity of vessels, with conventional capabilities of Optical Character Recognition (OCR) software. The extracted information went through a harmonization process whereby all port names were verified and disambiguated to avoid errors, as many of them changed over time, alongside decolonization trends for instance. The resulting tables were merged into one single maritime database, which served to construct a global origin-destination (or adjacency) matrix of inter-port maritime flows.

In the network (or graph), ports are considered as nodes (vertices), and flows between them as links (edges), to allow the calculation of standard network measures originating from graph theory (Ducruet and Lugo 2013). The following measures (see Appendix 1 for a graphical illustration) were retained to be calculated at the level of urban areas, the latter being defined in the next section. Degree centrality is the number of adjacent neighbor nodes connected to node $i$ as in formula (1), the most common measure for any node that expresses its actual connectivity at the local level of its neighborhood. Betweenness centrality is the number of shortest paths among all nodes on which node $i$ is located (2); it is more a global-level measure of network accessibility taking into account the entire graph. The clustering coefficient (3) is the proportion of observed triangles (or triplets, cliques) in the maximum possible number of triangles (or triplets, cliques) in the neighborhood of node $i$, which has the same distribution than the share of observed links in the maximum possible number of links in this neighborhood. This coefficient is low at ports being bridges or hubs in the network, i.e. which neighbors are poorly connected with each other, as in the star or hub-and-spokes configuration. Conversely, high values indicate that ports are part of more densely connected or meshed patterns. Lastly, 
the rich-club coefficient (4) corresponds to the density of the subgraph of larger cities (i.e. with a population higher than world average) divided by the density of the whole network; the density being defined as the proportion of actual links in the maximum possible number of links. Values over 1 signify that larger nodes (here in terms of population) are more densely connected with each other than the rest of the network, a phenomenon also known as the "rich-club effect". At the level of urban areas, such measures can reveal to what extent is maritime centrality of different kinds influenced by the urban weight of port nodes.

$$
\begin{aligned}
& \text { Degree centrality } k_{i}=C_{D}(i)=\sum_{j}^{N} x_{i j} \\
& \text { Betweenness centrality } C_{B}(i)=\frac{g_{j k}(i)}{g_{j k}} \\
& \text { Clustering coefficient } C_{i}=\frac{2\left|\left\{e_{j k}\right\}\right|}{k_{i}\left(k_{i}-1\right)} \\
& \text { Rich-club coefficient } \phi(k)=\frac{2 E_{>k}}{N_{>k}\left(N_{>k}-1\right)}
\end{aligned}
$$

\section{Ports and urban spatial structures}

This research benefited from the availability of demographic data in the Geopolis database, which provides the demographic size in urban areas over 100,000 inhabitants in 1990 based on morphological criteria over the period 1950-1990 (Moriconi-Ebrard 1994). As presented in Fig. 1, two levels of urban activity have been distinguished, city and urban area. The city level is the municipality where the port is located, i.e. the smallest administrative area that is often the eponym of the port itself. The urban area level is the agglomeration or urban morphological area, with two possibilities: the urban area to which the city belongs, or a more distant, inland urban area that connects by road the city, the latter being the maritime outlet of the former.

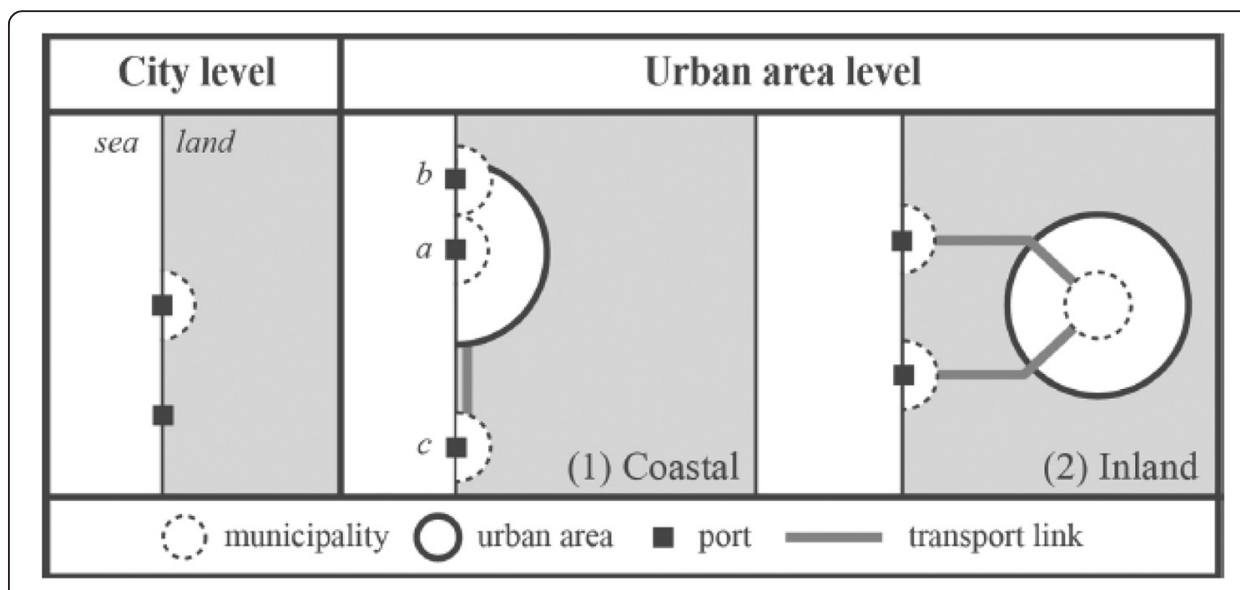

Fig. 1 Methodology for port-city matching. Source: own realization 
Each port or terminal was associated to the nearest urban center taking into account urbanization patterns, physical proximity, road accessibility, and urban system layout (see Appendix 2 for a description of quantiles). This manual method was preferred to any automatic matching in a Geographical Information System (GIS) to avoid putting together cross-border locations belonging to radically different historical or socioeconomic contexts. In addition to manual matching using the website Google Maps for locating each port within or near a given city or urban area, we used various portspecific websites to retrieve them, such as World Port Source, Maritime-Database, and Portfocus, as well as numerous websites of individual port authorities. In many cases, it had been necessary to verify the likely geographic extent of port hinterlands by consulting a wide variety of historical documents, which cannot be listed in this paper due to their number and diversity. Unfortunately, the absence of systematic information about hinterland flows could not help to delineate them with precision, which is a recurrent problem in port geography (Guerrero 2014), especially for studies having a historical focus. In any case, this method is a necessary simplification of reality to allow discussing the distribution of flows in relation to the size and dimension of the places of shipment (coastal urban area) and in some cases, the likely places of consumption/ production (inland urban area). Yet, vessel movements correspond to inter-port segments within a wider sequence of port calls, in which there is no information about the true origin and destination (and quantity) of the transported cargo.

Nevertheless, Fig. 2 introduces four recurrent cases of port-city matching, for instance with a large upstream urban center exerting its dominance upon a large number of estuarine ports up to the coast (London); a more polycentric, coastal urban system

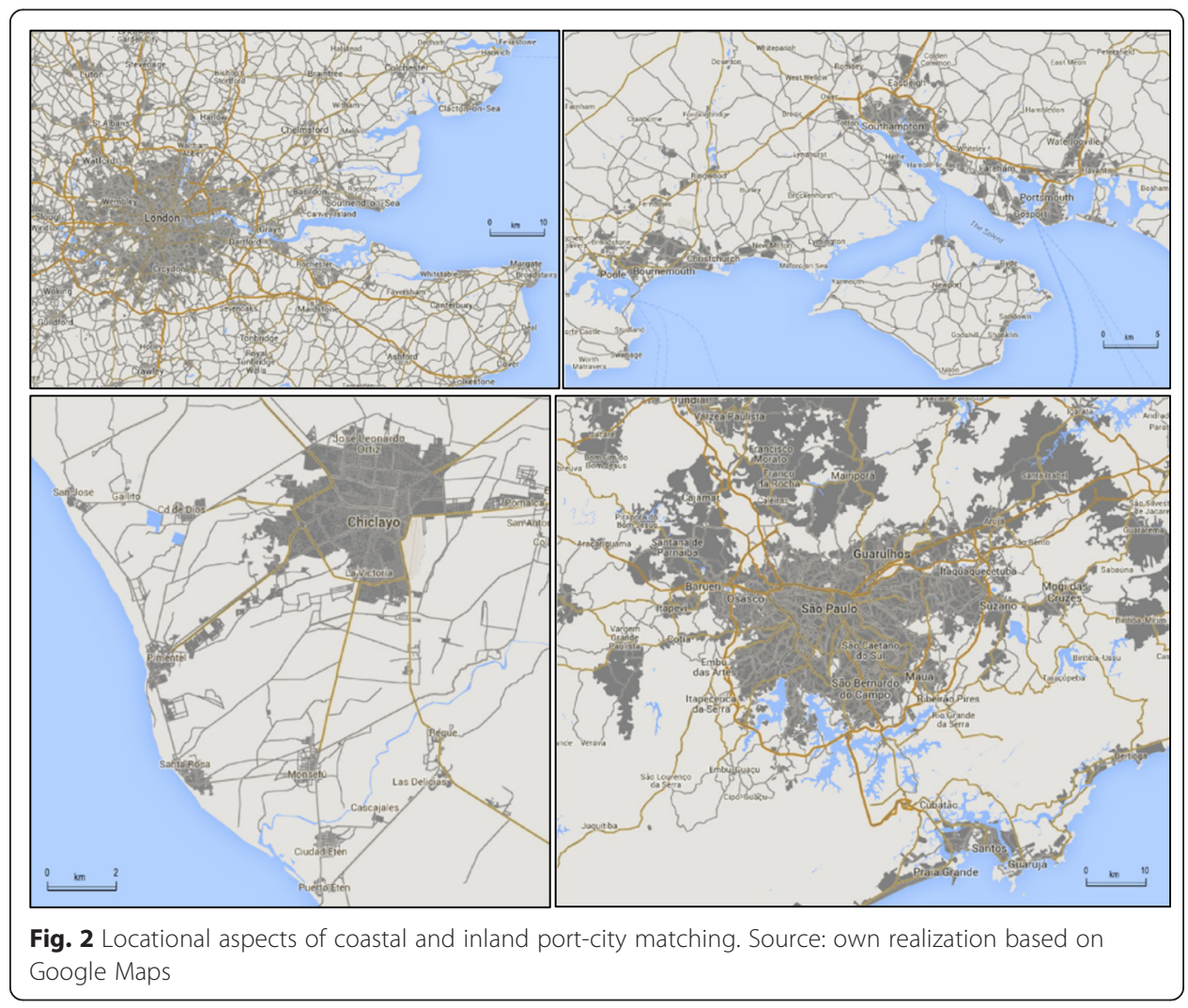


including cities of equivalent size and even composing conurbations (Southampton-Portsmouth, Bournemouth-Poole); an inland urban center located near the coast but having a road access to maritime transport through smaller coastal urban settlements (Chiclayo in Peru); and two major urban areas being connected over land with one single maritime access (Sao Paulo, Santos in Brazil). Such cases can easily be extended to other examples worldwide due to the general character of urban settlement patterns. Yet, the only drawback of this methodology is to ignore the historical evolution of urbanization, as settlement patterns were quite different in the 1950s compared with nowadays. In addition, certain cities (or communes, districts) at the administrative level did change their boundaries over time, creating a bias or Modifiable Area Unit Problem (MAUP). To enable our analysis on the 1950-1990 it was chosen to work only at the urban area (agglomeration) level and to consider that urban structures have been spatially relatively stable over time, despite urban sprawl and suburbanization (Bretagnolle 2009). As a result, it was possible to aggregate many terminals, ports, and cities altogether that in fact serve the same urban area, and gain in spatial coherence.

As a result and based on Fig. 1, the global port-urban database consisted in 529 urban areas having at least one vessel call between 1950 and 1990, such cities being directly matched with a port ( $a$ and $b$ in Fig. 1). This amount increased to 628 when matching additional ports to the closest urban area ( $c$ and inland in Fig. 1). These 628 cities concentrated a growing share of the total number of ports in the maritime database, from $51 \%$ in 1950 to $63 \%$ in 1990, but a slightly declining share of total world population (from 53 to $47 \%$ ) and world vessel calls (from 82 to $78 \%$ ). The additional hundred cities added a mere $14 \%$ of world traffic to the sample on average compared with the 529 cities. Despite the drop in traffic share, the latter remains very high and suggest that most of the world's maritime activity in fact concentrates at a limited number of urban places. Such a preliminary result already answers, at least partly, the initial hypothesis as a very high proportion of maritime flows concentrate at larger cities. The slight decline over the period is attributable to the exclusion of smaller cities from the Geopolis database, which tended to attract more traffic over time. In addition, we calculated that the urban areas under study are three times larger on average than other cities in terms of demographic size.

Additional preliminary results are provided in Table 1 and Fig. 3, which help to appreciate how much the geographical distribution of traffic and population has changed between 1950 and 1990. In 1950, most of the world's maritime traffic concentrated in the North Atlantic region, whereas in 1990, East Asia had become the leading region. The comparison with population implies that the two main indicators haven't evolved along similar ways, as seen with the tremendous urban population growth for instance in Latin America and South Asia that did not result in an equivalent traffic growth. Contrastingly in Europe, British port cities maintained their population but lost a considerable traffic share to the Le Havre - Hamburg range, the London case being a typical example of a declining port in that period, with the symbolic reconversion of its Docklands.

Lastly, the analyses proposed in this paper rested on two additional calculations. One of them consisted in distinguishing six classes of urban areas based on their demographic size (see Additional file 1 for a complete list of ports and urban areas). Using quantiles instead of arbitrary thresholds (e.g. over 1 million inhabitants) avoided the possible bias caused by the general increase of city sizes over time, and therefore the incomparability of citysystems from one period to the other. Quantiles depend on different population thresholds 
Table 1 Distribution of vessels calls at the world's demographically largest cities, 1950-1990

\begin{tabular}{|c|c|c|c|c|c|}
\hline \multirow[t]{2}{*}{ Port city } & \multicolumn{5}{|c|}{ Number of vessel calls } \\
\hline & 1950 & 1960 & 1970 & 1980 & 1990 \\
\hline London & 799 & 863 & 586 & 352 & 273 \\
\hline New York & 698 & 718 & 585 & 414 & 236 \\
\hline Calcutta & 275 & 301 & 233 & 141 & 67 \\
\hline Buenos Aires & 338 & 351 & 276 & 292 & 181 \\
\hline Lima & 23 & 51 & 79 & 30 & 65 \\
\hline Manila & 74 & 79 & 90 & 79 & 107 \\
\hline Jakarta & 40 & 77 & 81 & 83 & 107 \\
\hline Rio de Janeiro & 92 & 77 & 98 & 124 & 160 \\
\hline Sao Paulo & 90 & 113 & 109 & 202 & 156 \\
\hline Tianjin & 4 & 24 & 33 & 42 & 105 \\
\hline Bombay & 134 & 176 & 153 & 235 & 226 \\
\hline Taipei & 13 & 32 & 42 & 85 & 147 \\
\hline Karachi & 64 & 80 & 109 & 198 & 174 \\
\hline Shanghai & 25 & 87 & 118 & 119 & 188 \\
\hline Los Angeles & 229 & 239 & 252 & 371 & 456 \\
\hline Bangkok & 42 & 62 & 129 & 160 & 285 \\
\hline Nagoya & 16 & 56 & 184 & 212 & 263 \\
\hline Osaka & 117 & 399 & 555 & 458 & 593 \\
\hline Hong Kong & 144 & 216 & 311 & 362 & 602 \\
\hline Tokyo & 379 & 599 & 905 & 839 & 989 \\
\hline Sample share (\%) & 20.0 & 18.7 & 18.3 & 20.7 & 19.1 \\
\hline World total & 17,968 & 24,541 & 26,879 & 23,148 & 28,193 \\
\hline
\end{tabular}

Source: own realization based on Lloyd's Shipping Index and Geopolis data

N.B. 20 largest cities by the number of inhabitants for the year 1990; values in bold are higher than the row's average

between 1950 and 1990 but can be compared as each class contains the same proportion of cities, i.e. around $16.7 \%$. The second approach is the measurement of orthodromic distances (or great-circle distances, i.e. crow's fly distances taking into account the sphericity of the Earth) for each pair of connected urban areas in the maritime network. Such a measure is very helpful to verify to what extent larger cities connect geographically far-reaching maritime forelands, as it was demonstrated earlier in the case of airports in airline networks (Guimera et al. 2005) and of container ports in liner shipping networks (Ducruet and Zaidi 2012) but only in recent times. Further research may consider using nautical distances in order to better respect the contours of continents and coastlines.

\section{Main results}

\section{The changing influence of city-systems on maritime flows}

The first verification of urban influences on maritime traffic distribution and hierarchical tendencies among port cities was obtained by looking at the share of each quantile in world vessel traffic (Fig. 4). Additional statistics about the calculated quantiles are available in Appendix 2. Results were striking as the largest cities always concentrated the highest traffic share all over the period. The two larger quantiles Q6 and Q5 together concentrated nearly $80 \%$ of the total maritime traffic handled by all urban areas 


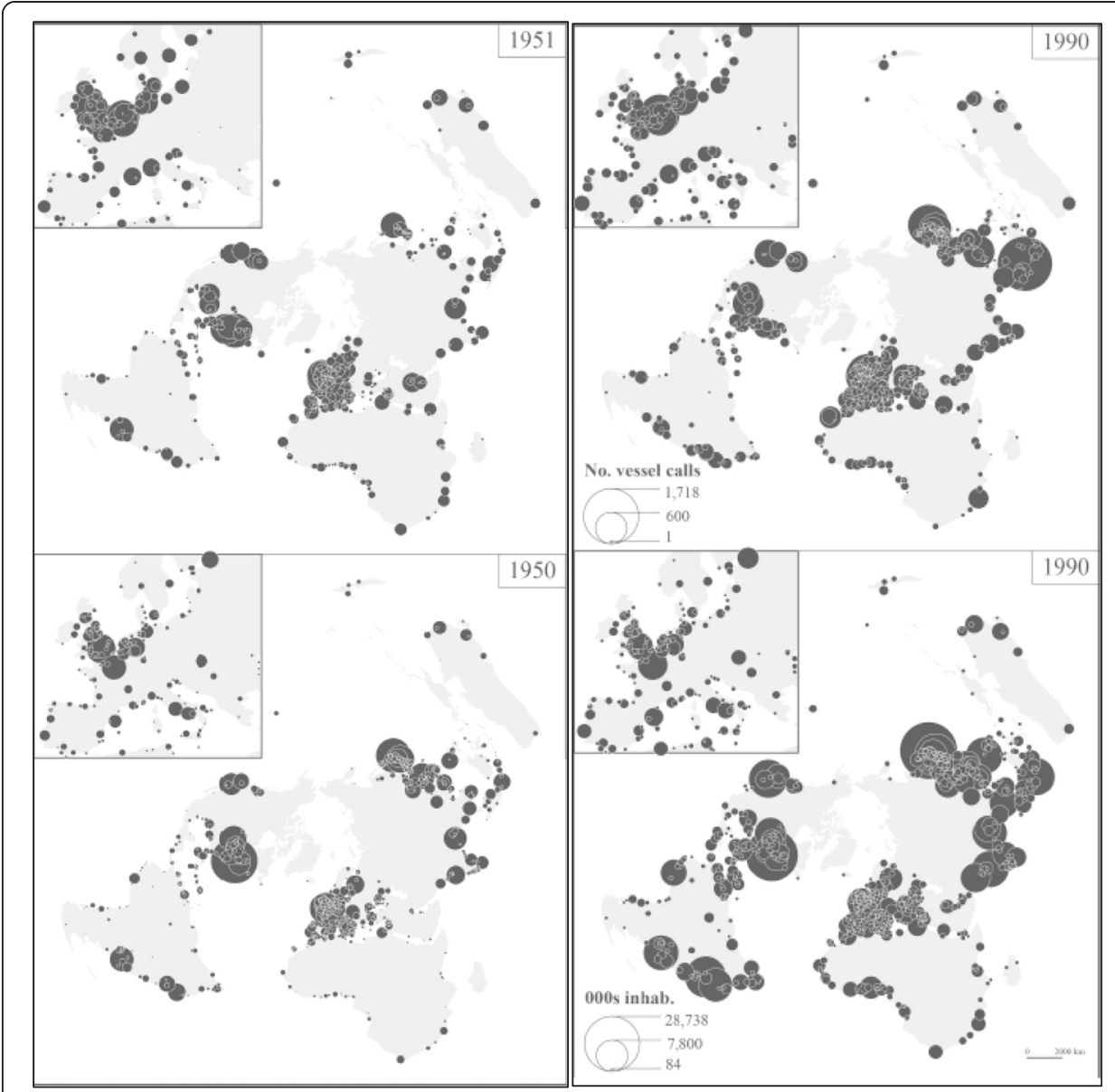

Fig. 3 World distribution of vessel calls and population by urban area, 1950 and 1990. Source: own realization based on Lloyd's Shipping Index and Geopolis data

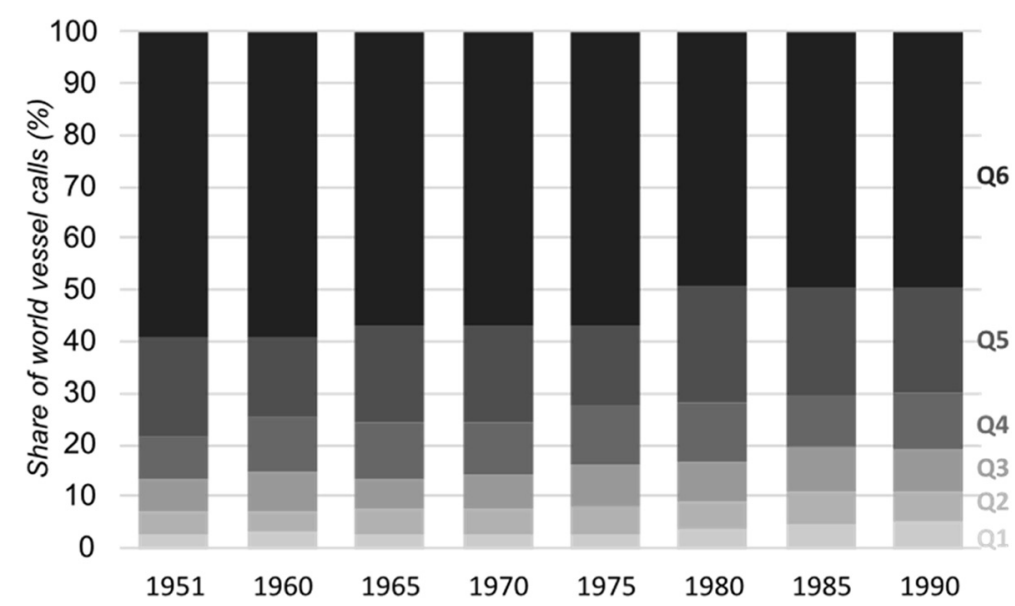

Fig. 4 Distribution of vessel calls per classes of urban demographic size, 1950-1990. Source: own realization based on Lloyd's Shipping Index and Geopolis data 
in 1950, and their combined share was still around $70 \%$ in 1990. The quantile of largest cities (Q6) alone fell from 60 to $50 \%$. This noticeable drop recalls the aforementioned preliminary results as part of world traffic tended to shift to smaller cities over the period. In turn, the share of the smallest cities (Q1) almost doubled, from 2.8 to $5.3 \%$. In other words, larger cities keep dominating global maritime flows, but they have been gradually challenged by smaller ones at the bottom of the urban hierarchy. In comparison, medium-sized cities' share had remained relatively stable over time. As seen in Appendix 2, similar evolutions can be observed when looking at the population share of quantiles, which would imply that traffic shares only reflect population shares. However, the average demographic size of quantiles marks contrasted evolutions, as for instance the largest cities (quantile 6) have a growing score, compared with the declining average size of vessel calls (see next Fig. 5). Such a result is a good illustration of the reorganization of maritime networks as described earlier, which had been well documented in early spatial models, and later extended on a larger scale by Hayuth (1981) in his discussion on the "challenge of the periphery". Early phases of port system development showed a rather linear trend by which one dominant port (city) accumulated traffic at the expense of its neighbors through a path-dependent process. Later phases added by subsequent scholars better outlined the de-concentration effects from core to periphery due to congestion, lack of space, and diseconomies of scale in large port gateways and load centers (see also Notteboom and Rodrigue 2005).

Complementarily, the average traffic size of the different quantiles (Fig. 5) confirmed the overwhelming dominance of the largest cities, with an average traffic size of about 150 vessel calls along the period, constantly increasing until 1975 and slightly decreasing afterwards. The same occurred for other quantiles, while the one of the smallest cities (Q1) kept increasing its average traffic size in the late period. This corroborates the previous results underlying the rise of smaller cities in global maritime activity.

At the level of individual urban areas, we calculated the Pearson correlation between the number of inhabitants and the number of vessel calls (Fig. 6). A similar result was

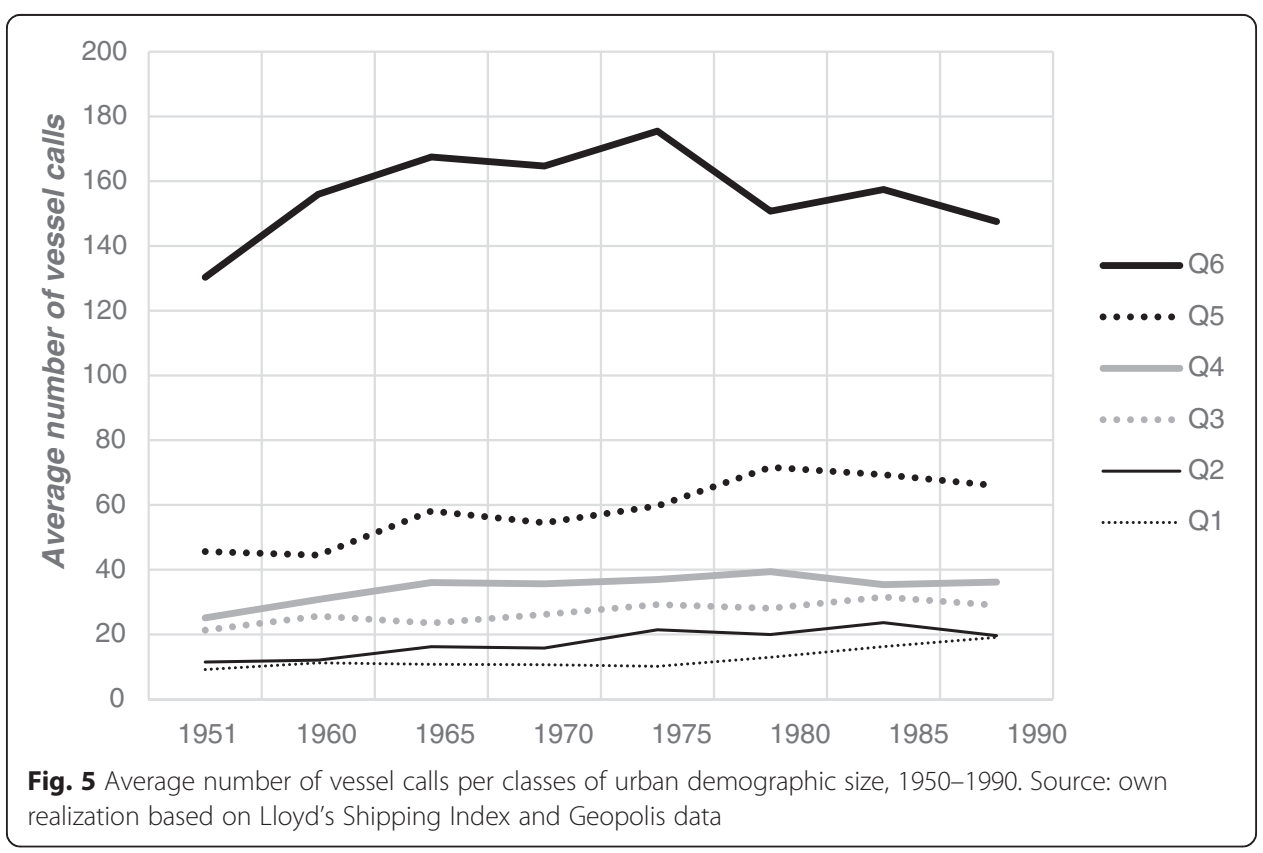




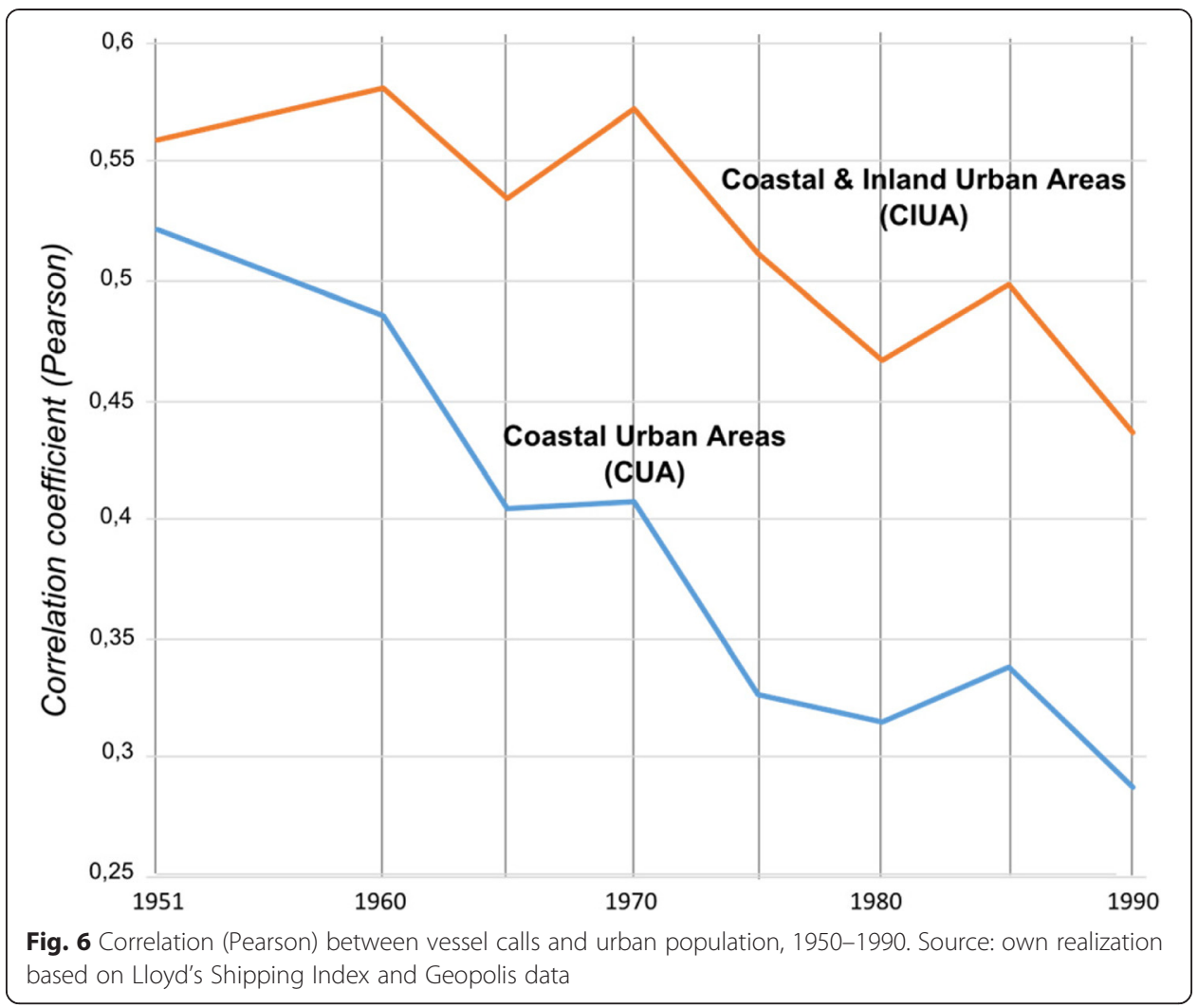

observable, namely the rapid drop of the port-city correlation. Comparable results were provided by Ducruet and Lee (2006) for the period 1970-2005: a growing share of largest cities in total traffic, a decreasing linear correlation with city size since the 1990s, but only based on container throughput and coastal cities. Yet, we also observed huge differences according to the sample of urban areas considered. The coefficient for coastal urban areas alone fell by half between 1950 and 1990, from 0.52 to 0.29 . This latter sample is made of urban areas hosting a port or are served by ports in very close proximity. The other sample (coastal and inland urban areas) includes the same coastal cities but also additional ports serving urban areas through farther distances, be it coastal or inland cities, the latter case being exemplified by Chiclayo city in Fig. 2. Such inland cities are often the true engine behind the traffic activity of coastal ports (see OECD 2014). Turning to our results, the coefficient for the second sample of urban areas also witnessed a noticeable drop, but far less than for coastal cities only. This reflects the "hinterland effect" exerted by inland cities upon coastal ports, also denoted the "tunnel effect" (Offner 1993) or "urban shadow" (Fujita and Mori 1996) by which smaller urban settlements economically benefit only partly from the presence of transport infrastructure, which rather serves more distant and larger ones. The traffic volume handled by seaports is thus better explained by city sizes when aggregating peripheral ports to their closest urban area. In some way this operation annihilates the effects discussed above in terms of peripheral challenge and de-concentration. Further research is needed to better distinguish the respective effects of inland and coastal cities on these results with, perhaps, additional information such as upstream river city, downstream river city, inland city, coastal city without river, and island. 


\section{Urban centrality in the global maritime network}

The next step in this analysis consists in considering maritime centrality measures instead of absolute weights like the number of vessel calls (Table 2). Overall, all centrality measures slightly declined in their statistical relationship with urban population between 1950 and 1990, with a bigger drop between 1980 and 1990. Degree centrality somewhat maintained a relatively significant correlation until 1980, and witnessed a lesser drop in 1990 than for betweenness centrality, a more global measure. This corroborates previous results in a sense that not only traffic volumes shifted from largest to smallest cities in the urban hierarchy, but also their accessibility and connectivity. On average, larger cities (with a population over the median value) are 5 times more densely connected than the rest of the network (rich-club coefficient), but a drop occurred from 5.6 to 4.8 over the period. The clustering coefficient is negatively correlated with demographic size because larger cities tend to be more central and therefore have lower clustering scores than smaller cities.

A closer look at the distribution of the average clustering coefficient by quantile is needed to further check such results (Fig. 7). Yet is should be noted that the average clustering coefficient for the entire network is much higher at urban area level than at port level, which denotes a strong effect of node aggregation on the network's structure. Results obtained by Ducruet et al. (2015) showed that the clustering coefficient also declined at port level, from 0.37 in 1951 to 0.26 in 1990, whereas in the present paper at urban area level, the same calculation showed a decline from 0.54 to 0.46 . The network of ports is thus more sparsely connected than the network of cities, due to the spatial scattering of many port nodes being in fact associated to the same urban gateway. In both cases however, the maritime network had evolved towards a hub-and-spokes or "scale-free" structure, alongside transformation of the port and maritime industries. Containerization appears as a likely cause, at least in part, of such trends, having caused the decline of numerous upstream urban ports (Baird 1996) whereas others such as Antwerp and Hamburg succeeded in maintaining and even reinforcing their maritime dominance despite site constraints (Notteboom et al. 1997). A look at the average values per quantile confirm that while all quantiles went through a structural centralization of flows, the largest cities maintained their dominance, with still the lowest score in 1990 compared with others. This means that the largest cities are the most likely to exert hub functions in the network, at least at the local level (the clustering coefficient is a local level measure), in other words to dominate their closest connected neighbors. Yet, the gap between smallest and largest

Table 2 Urban population and centrality measures, 1950-1990

\begin{tabular}{llllllll}
\hline Measures & 1951 & 1960 & 1970 & 1980 & 1990 & Interpretation \\
\hline $\begin{array}{l}\text { Linear } \\
\begin{array}{l}\text { correlation } \\
\text { Pearson) }\end{array}\end{array}$ & $\begin{array}{l}\text { Clustering } \\
\text { coefficient }\end{array}$ & -0.231 & -0.251 & -0.255 & -0.202 & -0.210 & Neighborhood centralization \\
$\begin{array}{l}\text { Degree } \\
\text { centrality }\end{array}$ & 0.462 & 0.521 & 0.469 & 0.465 & 0.423 & $\begin{array}{l}\text { Local (neighborhood) connectivity by } \\
\text { the number of links }\end{array}$ \\
$\begin{array}{l}\text { Betweenness } \\
\text { centrality }\end{array}$ & 0.507 & 0.494 & 0.449 & 0.452 & 0.344 & $\begin{array}{l}\text { Global maritime accessibility or } \\
\text { number of occurrences on shortest } \\
\text { routes }\end{array}$ \\
Rich-club coefficient & 5.597 & 5.959 & 5.166 & 4.974 & $4.843 \begin{array}{l}\text { Network density among larger cities } \\
\text { versus in the entire network }\end{array}$ \\
\hline
\end{tabular}

Source: own realization based on Lloyd's Shipping Index and Geopolis data N.B. Measures marked by (a) are calculated excluding zero values 


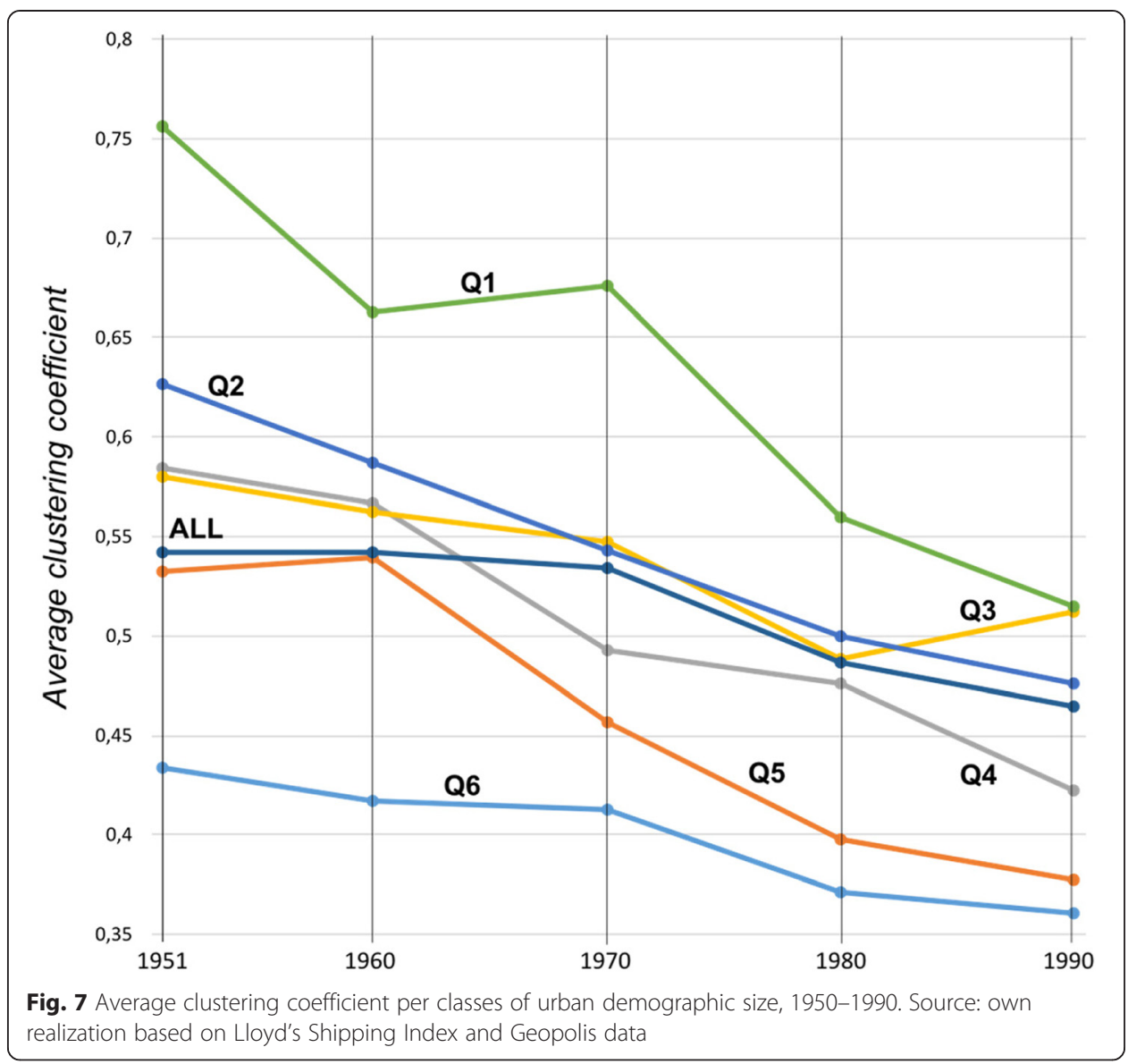

cities had narrowed over time, from 0.32 to 0.15 points, which also means that the hub functions of largest cities may have maintained but it had become more blurred than in the early period. In other words, there is an increasingly centralized network, but not necessarily by the largest cities only; hub functions had been redistributed across the urban hierarchy, even though largest cities still score better than smaller cities in 1990.

\section{Distance effects in maritime interactions among cities}

Intuitively and with regard to current results obtained in this paper, we hypothesize that larger cities should connect over farther maritime distances than smaller cities. One first result based on the calculation of simple orthodromic distances (Fig. 8, left), however, provided mixed evidence. On the one hand, it is clearly confirmed that the quantile of largest cities had always on average connected longer links. The links of largest cities are about 1.8 to 2 times longer than world average, immediately followed by Q5. Yet, the quantile of smallest cities (Q1) comes third by the impressive length of its links, longer than the remaining three quantiles with larger population. One likely explanation is that the smallest cities are connected via long-distance trades to largest cities, which in turn artificially flattens their geographic dominance. This seems to be a reasonable explanation, since the average distance does not increase much for Q1 in the late period, contrary to its traffic share. 


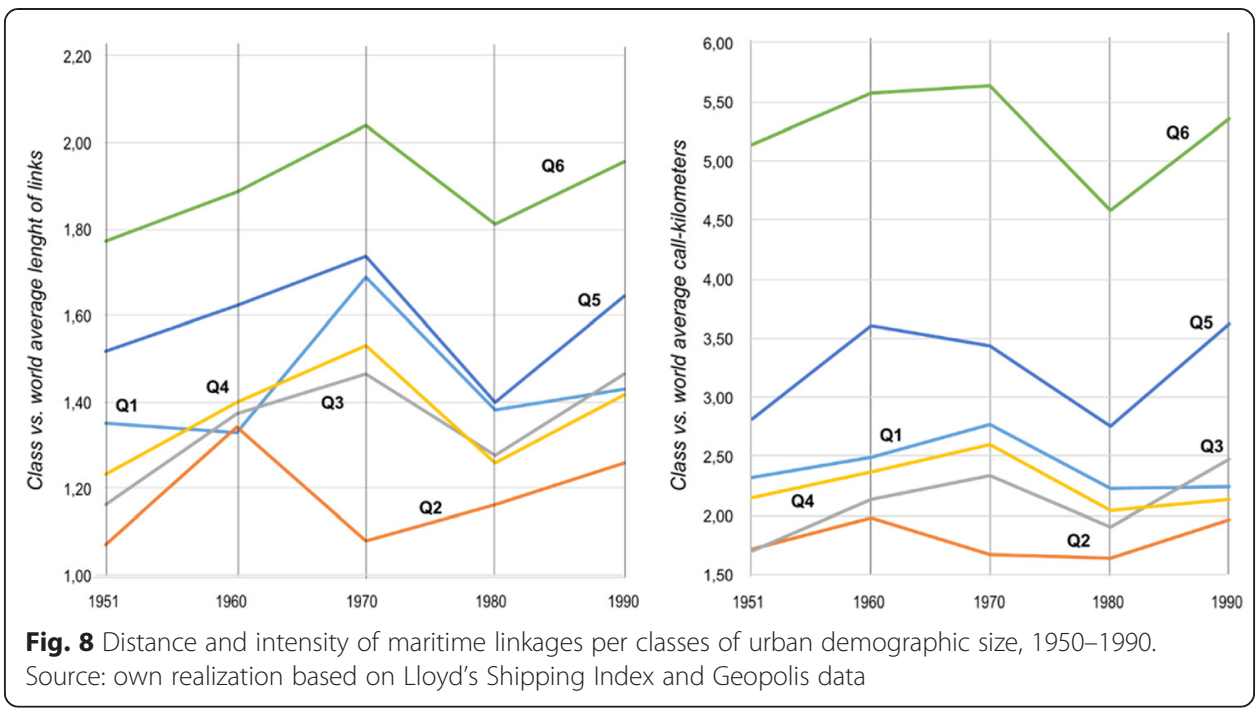

For such reasons it was decided to compare the results with the calculation of callkilometers (Fig. 8, right), a more standard measure of transport intensity in transport studies, which multiplies the travelled distance by the amount of flows (here vessel calls). Results were comparable according to the order of quantiles, but with a huge difference in terms of the gap between them. Still, the smallest cities were characterized by a noticeably higher call-kilometer intensity than demographically larger quantiles (Q2 to Q4). But their ratio over world average remained around 2.5 compared with 5 and 3.5 for Q6 and Q5, respectively. It means that the largest cities managed to maintain their geographic dominance far beyond smaller ones.

A more detailed picture of the association between urban population and flow distances was obtained by plotting together the demographic size and the sum of callkilometers by urban area (Fig. 9). The two distributions exhibited a very significant statistical fit in 1950 ( $\mathrm{r}^{2}$ of 0.74$)$, while it slightly dropped over time up to 0.55 in 1990. Yet, this correlation remains much more significant than the one between urban population and the sole vessel calls (without taking into account distances), which remained at the level of $0.67,0.64,0.60,0.53$, and 0.49 at respective years, i.e. $7 \%$ lower on average than with call-kilometers. Such a gap indicates that city sizes have a much better explanation power for geographic dominance than for sole traffic weights. Thus, the geographic coverage of maritime interactions is a good reflection of urban patterns, which was impossible to discover using usual port tonnage data. Still, the declining relationship between 1950 and 1990, as in previous results, is a sign that urban structures had gradually become less important to explain the intensity and spatial distribution of maritime networks.

\section{Conclusion}

This research constitutes the first-ever analysis of global maritime networks in relation to urban development. Complementary analyses converged in verifying positively the initial hypothesis that maritime networks are spatial networks which spatial distribution strongly depends on the local characteristics of its (port) nodes. At the same time, the influence of city sizes tended to diminish during the period under study (1950-1990), 


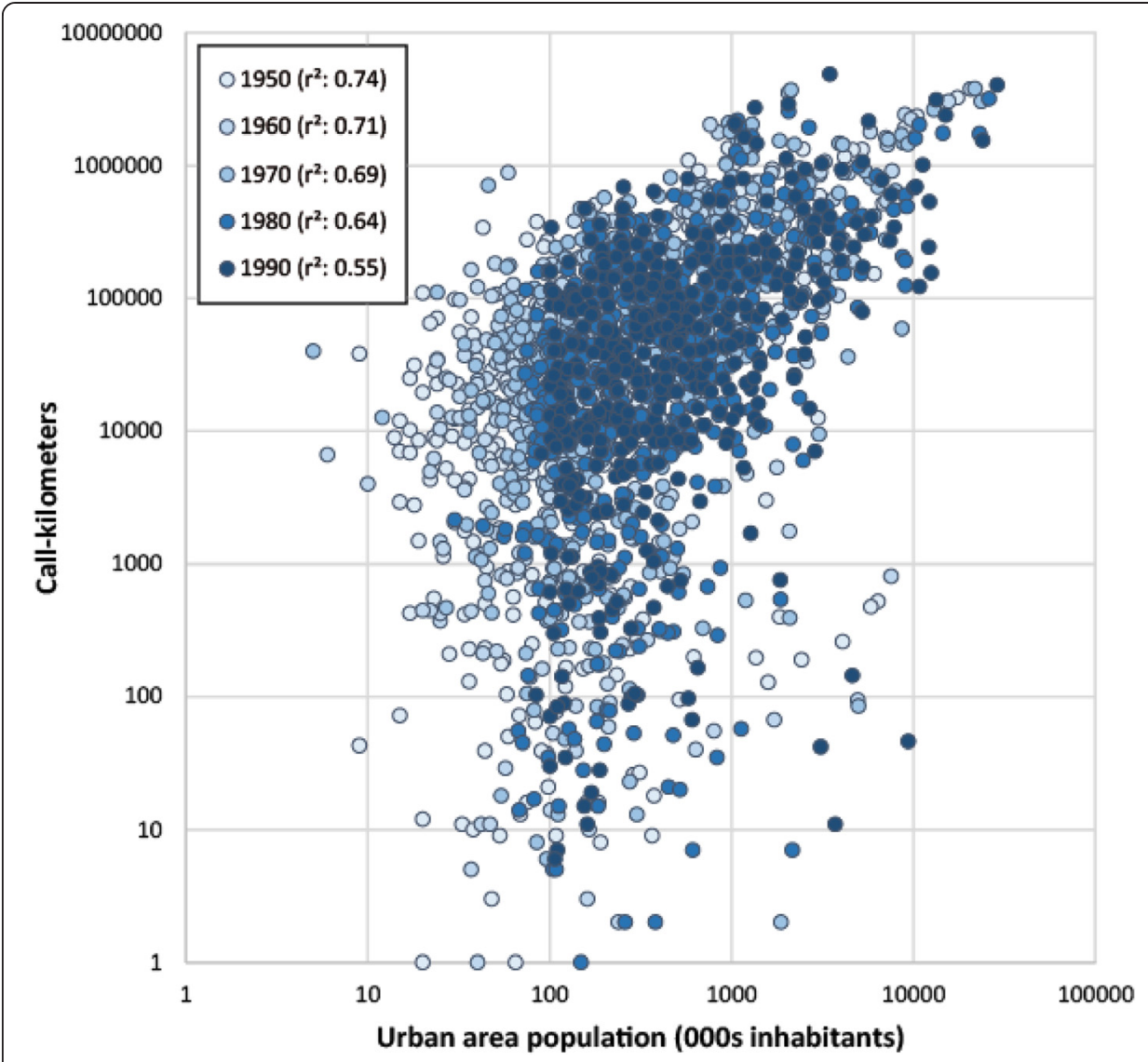

Fig. 9 Call-kilometer intensity and urban demographic size, 1950-1990. Source: own realization based on Lloyd's Shipping Index and Geopolis data

which corroborates the validity of early spatial models of port-city separation. Changing technological standards and trade patterns fostered port competition, traffic concentration, and network rationalization to such an extent that maritime networks and citysystems became gradually less overlapped at the global scale. The simplification of the network's structure motivated by time and cost reduction led to a decline in the number of intermediary port calls as ships increase in size and travel over longer distances. Still in 1990 however, the urban influence remains significant, especially in terms of maritime centrality and connectivity. At the same time, the world's largest cities lose and maintain their maritime functions. This paradoxical result can be largely attributed to the underlying geographic shifts of urban and maritime dominance across the world, in an age of rapid globalization.

Further research is needed to push further the understanding of mutual urban-maritime interdependencies. First, the inclusion of vessel sizes (tonnage capacity) would certainly strengthen our results only based on vessel calls, as well as the distinction amongst different types of maritime cargoes, such as breakbulk, containers, and bulks. Such a distinction would allow further analyses to verify the varying affinity of the urban mass to different traffic types and adopt a global value chain framework to such issues. Secondly, the availability of urban and maritime data over a longer time period motivates us to extend the analysis back in time and up to recent years (1890-2010). The global spread of 
production networks, increased economies of scale in liner shipping, and the China factor are examples of important dynamics taking place mainly in the post-1990 era. Thirdly, the sample of cities and urban areas should be enlarged to include smaller urban settlements and fully embrace the global urban hierarchy. Lastly, additional tools may be applied to the global database, such as spatial interaction models and network clustering techniques, in order to further estimate the influence of distance on interurban maritime flows. Possibly such approaches would integrate additional information layers into the port-city nexus, such as land-based and airline transport networks in order to provide a fully-fledged analysis of multimodal city-systems.

This research points to the necessity for decision-makers to further address the mutual importance of cities and maritime transport in their design of future planning and development policies. The gradual mismatch between port and urban hierarchies implies a growing importance of road transport over ever-increasing distances. Introducing more maritime transport in urban policies is necessary not only for coastal but also inland cities and provinces which objective is to reduce the congestion and environmental effects of road transport taking place between main maritime terminals and main consumption/production centres. Similarly, governments, transport ministries and supply chain actors should strengthen discussions about the negative externalities of traffic concentration in an ever smaller number of port gateways.

\section{Endnotes}

${ }^{1}$ For instance, El Hosni (2015) enumerated the following factors: continued growth of containerized trade, increasing ship size and drastic port selection, direct access to consumer markets, higher possibility of empty container repositioning, port international competition (e.g. planned shift of transshipment activities serving British ports from Rotterdam/Antwerp hub to London Gateway), stevedore domestic competition (e.g. $\mathrm{HPH}$ in Felixstowe, DPW in London Gateway), environmental pressure to reduce trucking flows to/from large cities and distant port terminals (e.g. London-Felixstowe, Taipei-Kaohsiung), cost saving of near-city shipping for shippers and their customers.

\section{Appendix 1}

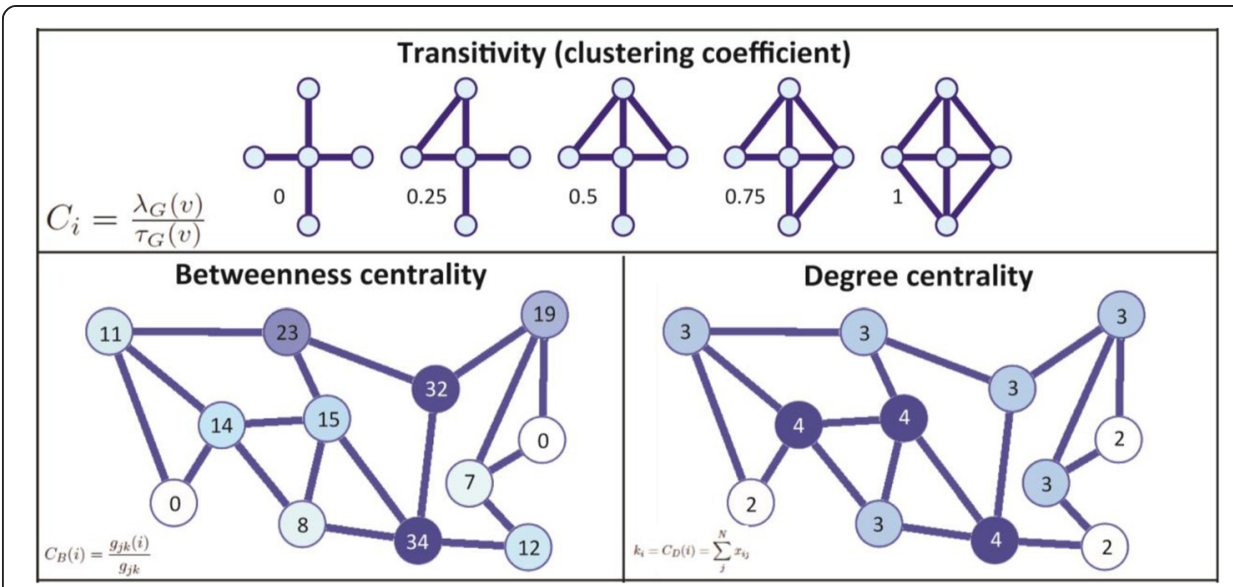

Fig. 10 Illustration of main network measures. Source: own realization 


\section{Appendix 2}

Table 3 Statistical characterization of demographic quantiles, 1950-1990

\begin{tabular}{|c|c|c|c|c|c|}
\hline \multirow[t]{2}{*}{ Quantiles } & \multicolumn{5}{|c|}{ Thresholds (000 s inhabitants) } \\
\hline & 1950 & 1960 & 1970 & 1980 & 1990 \\
\hline 1 & 9 & 6 & 5 & 30 & 84 \\
\hline 2 & 46 & 65 & 93 & 122 & 144 \\
\hline 3 & 90 & 114 & 139 & 193 & 230 \\
\hline 4 & 155 & 183 & 242 & 310 & 380 \\
\hline 5 & 290 & 351 & 441 & 532 & 633 \\
\hline 6 & 711 & 917 & 1,067 & 1,128 & 1,403 \\
\hline $6^{\mathrm{a}}$ & 17,363 & 20,548 & 23,585 & 25,978 & 28,738 \\
\hline \multirow[t]{2}{*}{ Quantiles } & \multicolumn{5}{|c|}{ Population share (\% inhabitants) } \\
\hline & 1950 & 1960 & 1970 & 1980 & 1990 \\
\hline 1 & 0.8 & 1.0 & 1.2 & 1.6 & 1.7 \\
\hline 2 & 1.9 & 2.1 & 2.3 & 2.7 & 2.6 \\
\hline 3 & 3.5 & 3.5 & 3.8 & 4.2 & 4.3 \\
\hline 4 & 6.4 & 5.9 & 6.5 & 7.2 & 7.0 \\
\hline 5 & 12.8 & 13.1 & 13.2 & 14.0 & 13.8 \\
\hline 6 & 74.6 & 74.3 & 73.0 & 70.3 & 70.5 \\
\hline World & 100.0 & 100.0 & 100.0 & 100.0 & 100.0 \\
\hline \multirow[t]{2}{*}{ Quantiles } & \multicolumn{5}{|c|}{ Mean population (000 s inhabitants) } \\
\hline & 1950 & 1960 & 1970 & 1980 & 1990 \\
\hline 1 & 28 & 42 & 61 & 93 & 117 \\
\hline 2 & 66 & 88 & 114 & 151 & 183 \\
\hline 3 & 119 & 148 & 185 & 245 & 292 \\
\hline 4 & 223 & 252 & 315 & 406 & 482 \\
\hline 5 & 439 & 531 & 647 & 789 & 956 \\
\hline 6 & 2,553 & 3,098 & 3,589 & 4,007 & 4,822 \\
\hline World & 574 & 693 & 817 & 949 & 1,145 \\
\hline \multirow[t]{2}{*}{ Quantiles } & \multicolumn{5}{|c|}{ Standard deviation (000 s inhabitants) } \\
\hline & 1950 & 1960 & 1970 & 1980 & 1990 \\
\hline 1 & 9 & 14 & 19 & 17 & 14 \\
\hline 2 & 13 & 15 & 14 & 22 & 23 \\
\hline 3 & 18 & 21 & 26 & 34 & 45 \\
\hline 4 & 42 & 50 & 57 & 68 & 70 \\
\hline 5 & 117 & 152 & 160 & 171 & 221 \\
\hline 6 & 2,731 & 3,302 & 3,982 & 4,377 & 4,780 \\
\hline World & 1,435 & 1,731 & 2,052 & 2,261 & 2,574 \\
\hline
\end{tabular}

Source: own realization based on Geopolis data

ahigher threshold of the last quantile 


\section{Additional file}

Additional file 1: List of ports and related urban areas. (PDF $250 \mathrm{~kb}$ )

\section{Competing interests}

The authors declare that they have no competing interests.

\section{Authors' contributions}

CD - Contribution: database elaboration, literature review, cartography, network analysis, interpretation and validation of results, and writing. SC - Contribution: database elaboration, interpretation and validation of results. AEH - Contribution: database elaboration, interpretation and validation of results. All authors read and approved the final manuscript.

Received: 4 February 2016 Accepted: 8 June 2016

Published online: 20 July 2016

\section{References}

Baird AJ (1996) Containerization and the decline of the upstream urban port in Europe. Marit Policy Manag 23(2):145-156 Barthelemy M (2015) Spatial networks: tools and perspectives. In: Ducruet C (ed) Maritime Networks. Spatial Structures and Time Dynamics. Routledge Studies in Transport Analysis, London and New York, p 50-60

Bernhofen DM, El-Sahli Z, Kneller R (2013) Estimating the effects of the container revolution on world trade, CESifo Working Paper Series No. 4136

Bird J (1963) The major seaports of the United Kingdom. Hutchinson, London

Bird J (1977) Centrality and cities. Routledge and Kegan Paul, London

Bird J (1983) Gateways: slow recognition but irresistible rise. Tijdschr Econ Soc Geogr 74(3):196-202

Braudel F (1979) Civilisation matérielle, économie et capitalisme. Armand Colin, Paris

Bretagnolle A (2009) Villes et réseaux de transport : des interactions dans la longue durée (France, Europe, Etats-Unis) Habilitation à Diriger des Recherches, Université de Paris I - Panthéon Sorbonne, Paris

Bretagnolle A (2015) City-systems and maritime transport in the long term. In: Ducruet C (ed) Maritime Networks. Spatial Structures and Time Dynamics. Routledge Studies in Transport Analysis, London and New York, p 27-36

Bretagnolle A, Pumain D, Vacchiani-Marcuzzo C (2009) The organisation of urban systems. In: Lane D, Pumain D, Van der Leeuw S, West G (eds) Complexity Perspectives in Innovation and Social Change. Springer, Dordrecht, p 197-220

Broeze F (1989) Brides of the sea: port cities of Asia from the $16^{\text {th }}-20^{\text {th }}$ centuries. University of Hawaii Press, Honolulu

Derudder B, Liu X, Kunaka C, Roberts M (2014) The connectivity of South Asian cities in infrastructure networks. J Maps 10(1):47-52

Dobruszkes F, Lennert M, Van Hamme G (2011) An analysis of the determinants of air traffic volume for European metropolitan areas. J Transp Geogr 19(4):755-762

Dogan M (1988) Giant cities as maritime gateways. In: Dogan M, Kasarda JD (eds) The metropolis era: a world of giant cities. SAGE Publications, London, pp 30-55

Ducruet C (2015) Maritime flows and networks in a multidisciplinary perspective. In: Ducruet C (ed) Maritime Networks: Spatial Structures and Time Dynamics. Routledge Studies in Transport Analysis, London and New York, p 3-26.

Ducruet C, Beauguitte L (2014) Network science and spatial science: review and outcomes of a complex relationship. Netw Spat Econ 14(3-4):297-316

Ducruet C, Itoh H (2015) The mutual specialization of port regions connected by multiple commodity flows in a maritime network. In: Ducruet C (ed) Maritime Networks. Spatial Structures and Time Dynamics. Routledge Studies in Transport Analysis, London and New York, p 285-302

Ducruet C, Lee SW (2006) Frontline soldiers of globalisation: port-city evolution and regional competition. GeoJournal 67(2):107-22

Ducruet C, Lugo I (2013) Cities and transport networks in shipping and logistics research. Asian Journal of Shipping and Logistics 29(2):149-170

Ducruet C, Zaidi F (2012) Maritime constellations: a complex network approach to shipping and ports. Marit Policy Manage 39(2):151-168

Ducruet C, Haule S, Ait-Mohand K, Marnot B, Kosowska-Stamirowska S, Didier L, Coche MA (2015) Maritime shifts in the contemporary world economy. Evidence from the Lloyd's List corpus, eighteenth to twenty-first centuries. In: Ducruet C (ed) Maritime Networks. Spatial Structures and Time Dynamics. Routledge Studies in Transport Analysis, London and New York, p 134-160

El Hosni A (2015) Le retour du port dans la ville, Unpublished master dissertation in geography. University of Paris 4 Sorbonne, Paris

Fujita M, Mori T (1996) The role of ports in the making of major cities: self-agglomeration and hub-effect. J Dev Econ 49(1):93-120

Gipouloux F (2009) La Méditerranée asiatique, villes portuaires et réseaux marchands en Chine, au Japon et en Asie du Sud-Est, XVle-XXle siècle. CNRS Éditions, Paris

Guerrero D (2014) Deep-sea hinterlands: some empirical evidence of the spatial impact of containerization. J Transp Geogr 35:84-94

Guerrero D, Rodrigue JP (2014) The waves of containerization: shifts in global maritime transportation. J Transp Geogr 35:151-164

Guimera R, Mossa S, Turtschi A, Amaral LAN (2005) The worldwide air transportation network: anomalous centrality community structure, and cities' global roles. Proc Natl Acad Sci U S A 102(22):7794-7799

Hall PV, Hesse M (2012) Cities, regions and flows. Routledge, Abingdon

Hall PV, Jacobs W (2012) Why are maritime ports (still) urban, and why should policy makers care? Marit Policy Manag 39(2):189-206 
Hayuth Y (1981) Containerization and the load center concept. Econ Geogr 57(2):160-176

Hoyle BS (1989) The port-city interface: trends, problems, and examples. Geoforum 20(4):429-35

Jacobs W, Koster HRA, Hall PV (2011) The location and global network structure of maritime advanced producer services. Urban Stud 48(13):2749-2769

Lee SW, Song DW, Ducruet C (2008) A tale of Asia's world ports: the spatial evolution in global hub port cities. Geoforum 39:372-385

Moriconi-Ebrard F (1994) Geopolis: Pour Comparer les Villes du Monde. Anthropos, Paris

Murphey R (1989) On the evolution of the port city. In: Broeze F (ed) Brides of the sea: port cities of Asia from the $16^{\text {th }}-20^{\text {th }}$ centuries. University of Hawaii Press, Honolulu, pp 223-245

Musso E, Benacchio M, Ferrari C (2000) Ports and employment in port cities. Int J Maritime Econ 2(4):283-311

Neal ZP (2011) The causal relationship between employment and business networks in US cities. J Urban Aff 33(2):167-184

Nelson A (2008) Travel time to major cities: a global map of accessibility. Global Environment Monitoring Unit, Joint Research Centre of the European Commission, Ispra

Ng AKY, Ducruet C (2014) The changing tides of port geography (1950-2012). Prog Hum Geogr 38(6):785-823

Ng AKY, Ducruet C, Jacobs W, Monios J, Notteboom TE, Rodrigue JP, Slack B, Tam KC, Wilmsmeier G (2014) Port geography at the crossroads with human geography: between flows and spaces. J Transp Geogr 41:84-96

Noin D (1999) La population des littoraux du monde. L'Information Géographique 63(2):65-73

Norcliffe G, Bassett K, Hoare T (1996) The emergence of postmodernism on the urban waterfront: geographical perspectives on changing relationships. J Transp Geogr 4(2):123-34

Notteboom TE, Rodrigue JP (2005) Port regionalization: towards a new phase in port development. Marit Policy Manag 32(3):297-313

Notteboom TE, Coeck C, Verbeke A, Winkelmans W (1997) Comment: containerization and the competitive potential of upstream urban ports in Europe. Marit Policy Manag 24(3):285-289

OECD (2014) The Competitiveness of Global Port-Cities. OECD Publishing, Paris

Offner JM (1993) Les « effets structurants » du transport : mythe politique, mystification scientifique. L'Espace Géographique 22(3):233-242

Parshani R, Rozenblat C, letri D, Ducruet C, Havlin S (2010) Inter-similarity between coupled networks. Europhys Lett (EPL) 92:68002

Pearson MN (1998) Port cities and intruders. John Hopkins University Press, Baltimore \& London

Robinson R (1968) Spatial Structuring of Port-Linked Flows: The Port of Vancouver, Canada, 1965. PhD Dissertation in Geography, University of British Columbia

Slack B (1993) Pawns in the game: ports in a global transportation system. Growth Change 24(4):579-588

Smith A (1776) An inquiry into the nature and causes of the wealth of nations. Methuen \& Co., Ltd., London

Ullman EL (1949) Mapping the world's ocean trade: a research proposal. Prof Geogr 1(2):19-22

Vance JE (1970) The merchant's world. The geography of wholesaling. Prentice-Hall, Englewood Cliffs

Verhetsel A, Sel S (2009) World maritime cities: from which cities do container shipping companies make decisions? Transp Policy 16(5):240-250

Vigarié A (1979) Ports de commerce et vie littorale. Hachette, Paris

\section{Submit your manuscript to a SpringerOpen ${ }^{\circ}$ journal and benefit from:}

- Convenient online submission

Rigorous peer review

- Immediate publication on acceptance

Open access: articles freely available online

- High visibility within the field

- Retaining the copyright to your article 